\title{
Gestão Estratégica da Propriedade Intelectual: um estudo sobre o Núcleo de Inovação Tecnológica do Instituto Federal Baiano no contexto do novo marco legal da Ciência, Tecnologia e Inovação (CT\&l)
}

\author{
Strategic Management of Intellectual Property In Scientific and \\ Technological Institutions (ICTS): a study on the Technological \\ Innovation core of the Baian Federal Institute in the context of the new \\ legal framework for Science, Technology and Innovation
}

\author{
Sandra Santos Souza ${ }^{1}$ \\ André Luis Rocha de Souza ${ }^{1}$ \\ Ângela Maria Ferreira Lima ${ }^{1}$ \\ Márcio Luis Valença Araújo ${ }^{1}$ \\ ${ }^{1}$ Instituto Federal de Educação, Ciência e Tecnologia da Bahia, Salvador, BA, Brasil
}

\begin{abstract}
Resumo
A pesquisa tem por objetivo analisar as forças, oportunidades, fraquezas e ameaças relacionadas ao Núcleo de Inovação Tecnológica (NIT) do Instituto Federal Baiano (IF Baiano) em face do contexto trazido pelo novo Marco Legal da Ciência, Tecnologia e Inovação (CT\&I) instituído pela Lei n. 13.243/2016. Este trabalho apresenta abordagem qualitativa, de natureza exploratória, e uso de pesquisa documental. Para tanto, foram coletados dados secundários para o diagnóstico das Forças, Oportunidades, Fraquezas e Ameaças - Matriz FOFA (do inglês SWOT). As constatações dos pontos fortes e fracos do NIT/IF Baiano são importantes para auxiliar nas decisões dos gestores e para apoiar ações que favoreçam o incremento da inovação tecnológica. Conclui-se que o setor deve continuar se fortalecendo nas legislações de inovação para o fomento tecnológico e científico com o intuito de obter soluções e benefícios para a sociedade.
\end{abstract}

Palavras-chave: Gestão Estratégica. Propriedade Intelectual. Núcleo de Inovação Tecnológica. Planejamento Estratégico.

\begin{abstract}
The research aimed to analyze the strengths, opportunities, weaknesses and threats related to the Technological Innovation Center of the Federal Institute of Bahia (NIT/IF Baiano), in view of the context brought by the new Legal Framework of Science, Technology and Innovation established by Law n. 13,243/2016. This paper presents a qualitative approach, exploratory nature and use of documentary research. For this, secondary data were collected for the diagnosis of Forces, Opportunities, Weaknesses and Threats - SWOT Matrix. Findings of the strengths and weaknesses of NIT/IF Baiano are important to assist managers' decisions and support actions that favor the increase of technological innovation. It is concluded that the sector must continue to be strengthened in innovation legislation for technological and scientific promotion aiming at solutions and benefits to society.
\end{abstract}

Keywords: Strategic Management. Intellectual Property. Technological Innovation Center. Strategic Planning.

Área Tecnológica: Administração. Gestão Estratégica. Propriedade Intelectual. 


\section{Introdução}

O crescimento de novas tecnologias e mudanças decorrentes do Novo Marco Legal da Ciência, Tecnologia e Inovação (CT\&I), instituído pela Lei n. 13.243/2016 e regulamentado pelo Decreto n. 9.283/2018, vem possibilitando uma nova perspectiva para as Instituições Científicas, Tecnológicas e de Inovação (ICTs) relacionadas à transferência de tecnologia para disseminação da inovação tecnológica (BRASIL, 2016a; 2018). Assim, a aplicação de instrumento estratégico pode propiciar as percepções do ambiente laboral, dando suporte aos gestores dessas instituições no processo de tomada de decisão e no direcionamento institucional. Segundo Guerreiro (2018), esse aparato estratégico auxilia o gestor das ICTs com uma projeção futura, clara e objetiva do que a instituição pode prover, levando em consideração seus pontos fracos, os quais são os que precisam ser refinados, e seus pontos fortes que, quando bem empregados, podem ser transformados em oportunidades, avaliando também aqueles que podem diminuir o potencial da organização.

Diante do exposto, a ferramenta Matriz FOFA - Forças, Oportunidades, Fraquezas e Ameaças (do inglês SWOT - Strengths, Weaknesses, Opportunities and Threats), que elenca esses fatores do ambiente organizacional, é uma ferramenta de gestão que contribui para a compreensão da realidade organizacional, por meio do diagnóstico que permite aos gestores compreender a realidade institucional e contribuir com o desenvolvimento do planejamento estratégico e com o plano de ação. De acordo com Fernandes (2012), a partir das percepções e dos conhecimentos dos ambientes internos que são consideradas as forças (Strengths) e as fraquezas (Weaknesses) da organização, e dos ambientes externos que são as oportunidades (Opportunities) e as ameaças (Threats), pode-se construir uma eficiente estratégia de inovação para as entidades, sejam elas públicas ou privadas. Assim, esse ambiente construído pelo pensamento estratégico dos componentes envolvidos deve levar em consideração os fatores críticos e os objetivos da organização, o que pode impulsionar e direcionar a busca de melhores resultados institucionais.

Assim, no âmbito das ICTs, em particular as públicas, a utilização da matriz FOFA como mecanismo de planejamento estratégico poderá contribuir para a formulação de objetivos estratégicos associados à produção científica e tecnológica institucional e ao desenvolvimento e crescimento dos indicadores de qualidade, além de colaborar, juntamente com a política de inovação institucional, para que a produção tecnológica possa chegar à sociedade.

Em face do exposto e diante do quadro de crise econômica e financeira que o Brasil vem passando, com reflexos tanto nas instituições públicas quanto na iniciativa privada, planejar estrategicamente as organizações torna-se tarefa fundamental para assegurar a continuidade de suas atividades. Nesse contexto, destaca-se a importância de um planejamento estratégico nas ICTs públicas, em particular nos Institutos Federais de Educação, Ciências e Tecnologia (IFETs), que, segundo o artigo $1^{\circ}$, parágrafo único, da Lei n. 11.892/2008 (Lei que os criaram), possuem "[...] natureza jurídica de autarquia, detentoras de autonomia administrativa, patrimonial, financeira, didático-pedagógica e disciplinar, cuja finalidade, conforme prevê o artigo $7^{\circ}$, inciso III, é: “"[...] pesquisas aplicadas, estimulando o desenvolvimento de soluções técnicas e tecnológicas, estendendo seus benefícios à comunidade "[...]", com oferta de cursos superiores de tecnologia, licenciaturas, bacharelados e engenharias, além de pós-graduação lato e stricto sensu - que "[...] contribuam para promover o estabelecimento de bases sólidas em educação, ciência e tecnologia, com vistas no processo de geração e inovação tecnológica" (BRASIL, 2008, p. 1). 
A fim de viabilizar a produção científica e tecnológica e promover a inovação, os Institutos Federais (IFs) contam com os Núcleos de Inovação Tecnológica (NITs), que, conforme estabelece a Lei de Inovação o Novo marco Legal da CT\&I (Lei n. 13.243/2016), consiste em "[...] estrutura instituída por uma ou mais ICTs, com ou sem personalidade jurídica própria, que tenha por finalidade a gestão de política institucional de inovação e por competências mínimas as atribuições previstas nesta Lei" (BRASIL, 2016a; 2004, p. 1).

Diante desse contexto e considerando a relevância dos IFs para o desenvolvimento científico e tecnológico nacional e, em particular, em âmbito regional e local, ressalta-se o papel do Instituto Federal de Educação, Ciência e Tecnologia Baiano (IF Baiano) que tem como missão ofertar gratuitamente variadas modalidades de educação profissional e tecnológica de qualidade, com atuações voltadas ao ensino, à pesquisa e à extensão, com ações em diversas dimensões territoriais de identidade e se estrutura no formato Multicampi que visa a garantir a interiorização da educação profissional na Bahia. Contudo, essa instituição ainda não dispõe de uma Política de Inovação Institucional, apesar de já dispor de um NIT desde 2016. Assim, considerando a missão do IF Baiano, bem como os objetivos do seu NIT que foi regulamentado pelo seu Regimento Interno em 2016 e veio atender ao novo Marco legal da CT\&I, questiona-se: Quais as forças, oportunidades, fraquezas e ameaças ao Núcleo de Inovação Tecnológica do Instituto Federal Baiano (NIT/IF Baiano), em face do contexto trazido pelo Novo Marco Legal da Ciência, Tecnologia e Inovação (CT\&I) instituído pela Lei n. 13.243/2016?

Desse modo, esta pesquisa tem o objetivo de analisar as forças, oportunidades, fraquezas e ameaças relacionadas ao Núcleo de Inovação Tecnológica do Instituto Federal Baiano (NIT/IF Baiano), em face do contexto trazido pelo Novo Marco Legal da Ciência, Tecnologia e Inovação (CT\&I) instituído pela Lei n. 13.243/2016.

Cabe destacar que o Novo Marco Legal da CT\&I é um dispositivo que proporciona a implantação de políticas públicas que ajudam no crescimento de espaços inovadores e colaborativos e estimulam a transferência de tecnologia entre as diversas ICTs. Por isso que os NITs têm um papel fundamental nesse direcionamento, pois, ao terem um planejamento estratégico eficaz com a realização do seu diagnóstico setorial por meio da identificação dos pontos fracos e fortes, poderão gerar um ambiente inovador e com visão de futuro, com o propósito de expandir benefícios para toda a sociedade com criação de novas tecnologias. Portanto, esta pesquisa se justifica pelas contribuições práticas que pode gerar, as quais poderão auxiliar os gestores e servidores do NIT/IF Baiano na concepção de sua política de inovação, diante do Novo Marco Legal da CT\&I, bem como apoiar o processo de tomada de decisão, direcionar a produção tecnológica e contribuir com a continuidade de oferta de serviços de qualidade para a população e com o desenvolvimento local e regional.

\section{Referencial Teórico}

O referencial teórico é dividido em duas seções, Inovação Tecnológica e as ICTs Públicas, e aborda o impulsionamento de tecnologias por essas organizações que visam a contribuir com o desenvolvimento brasileiro. A segunda seção, o Planejamento Estratégico e sua Importância para o Desenvolvimento Tecnológico dos IFETS, refere-se ao papel dessa ferramenta estratégica no auxílio do eficaz desempenho das ações institucionais na geração de inovações. 


\subsection{Inovação Tecnológica e as ICTs Públicas}

O estímulo ao desenvolvimento tecnológico voltado para a proteção e os direitos da Propriedade Industrial, Lei n. 9.279/96, incitou a publicação da Lei da Inovação no Brasil. A Lei n. 10.973/2004, conhecida como Lei de Inovação, instituiu interações entre empresas e ICTs públicas para formação de convênios e transferência de tecnologia, impulsionando a inovação tecnológica (BRASIL, 1996; 2004).

Em pouco mais de uma década houve modificações desse dispositivo (Lei n. 10.973/2004), por meio da Lei n. 13.243/2016, que instituiu o novo marco legal da inovação, formulada para expandir o incentivo à inovação, ao crescimento científico e tecnológico do Estado brasileiro, por meio das ICTs que devem reforçar a propagação de tecnologia em diversos ambientes de inovação. $\mathrm{O}$ artigo $1^{\circ}$, inciso VI, da referida Lei, reforça o estímulo "[...] à atividade de inovação nas Instituições Científica, Tecnológica e de Inovação (ICTs) e nas empresas, inclusive para a atração, a constituição e a instalação de centros de pesquisa, desenvolvimento e inovação e de parques e polos tecnológicos no País" (BRASIL, 2016a, p. 1). Na sequência, no ano de 2018, houve a normatização do Decreto n. 9.283/2018 que regulamentou a Lei n. 13.243/2016 e introduziu regras de estímulo à inovação e à capacidade tecnológica para aditamento do sistema produtivo do país, viabilizando a autonomia tecnológica desse ambiente para promoção da inovação abalizada no conhecimento científico e tecnológico (BRASIL, 2018).

A Lei n. 13.243/2016, alterou o artigo $1^{\circ}$ da Lei da Inovação, dispondo normas de estímulo à inovação, bem como a produção científica e tecnológica direcionado ao ambiente produtivo, visando à capacitação tecnológica para atingir a independência tecnológica e ao desenvolvimento econômico do setor produtivo brasileiro (BRASIL, 2016a). Esse dispositivo foi promulgado conferindo novas atribuições e responsabilidades aos Núcleos de Inovação Tecnológica (NITs) para o fomento a inovação tecnológica das ICTs.

Para Bagnato, Ortega e Marcolan (2016), o uso de ferramentas disponibilizadas pelas ICTs proporciona grande relevância na incitação da competitividade, pois o incentivo à pesquisa é crucial para esse encadeamento, sendo uma das elementares fontes do surgimento de novos conhecimentos e tecnologias. Assim, a busca por inovação requer a promoção de convênios e de interações das ICTs com o mercado, no intuito de criar laços mais prolongados e mútuos entre universidades, Institutos Federais de Educação, Ciências e Tecnologia (IFETs), institutos de pesquisas e empresas públicas ou privadas no bom emprego de oportunidades para o progresso e de instituições de inovações complacentes para o país. Portanto, cabe destacar o papel que as ICTs públicas desenvolvem nesse cenário de desenvolvimento de novas tecnologias, pois são entidades que buscam acelerar o país e minimizar os problemas de interesses sociais utilizando da aplicação do estudo científico e tecnológico para descoberta de novas tecnologias e produtos voltados para a sociedade.

A tecnologia aliada ao conhecimento fortalece a inovação que tem um papel importante no desenvolvimento econômico de muitos países. Isso porque, a cada dia vêm surgindo novos serviços, produtos e processos colaborando para que possam gerar mais riquezas com o propósito de alavancar a economia e de ajudar na qualidade de vida da sociedade. Conforme prevê o Manual de Oslo (OCDE, 2018, p. 20, tradução nossa), 
[...] inovação é um produto ou processo novo ou aprimorado (ou uma combinação dos mesmos) que difere significativamente dos produtos ou processos anteriores da unidade e que foi disponibilizado para usuários em potencial (produto) ou utilizado pela unidade (processo) ${ }^{1}$.

Cabe destacar que o estímulo à inovação tecnológica no Novo Marco Legal da Ciência, Tecnologia e Inovação (CT\&I) fortalece as ICTs, cuja consolidação dessas instituições passam por uma integração de vários instrumentos que vão desde o diálogo entre empresas e ICTs, como também por meio das qualificações de profissionais, publicações de pesquisas científicas, desenvolvimentos de tecnologias inovadoras, consultorias, incubação de empresas de base tecnológica, entre outros (BAGNATO; ORTEGA; MARCOLAN, 2016).

Conforme aponta o Ministério da Ciência, Tecnologia, Inovações e Comunicações (MCTIC), "[...] o desenvolvimento econômico dos países está assentado, cada vez mais, na inovação baseada no desenvolvimento científico e tecnológico" (BRASIL, 2016, p. 7). Resta claro, a partir dessa afirmação, o papel das universidades e Institutos Federais (IFs), já elas têm o propósito de propagar o conhecimento científico e tecnológico, oferecendo ensino de qualidade para capacitar a comunidade acadêmica e contribuir no desenvolvimento do país com criação de novas tecnologias.

Nesse contexto, reforça-se a importância de as ICTs públicas, com o intermédio de seus NITs, realizarem boas práticas de gestão, a fim de incorporar à inovação como diferencial competitivo de desenvolvimento tecnológico. Os NITs, que são responsáveis pelo planejamento $e$ execução das políticas de inovações dessas ICTs, passaram a ter novas atribuições a partir do Novo Marco Legal, conforme prevê o artigo 16 da Lei n. 13.243/2016, no seu $\S 1^{\circ}$, alínea de VII a X, o que requer uma atuação mais ativa para desbravar novas perspectivas e ações estratégicas, visando a captar parcerias com empresas do setor público ou privado para expansão da inovação (BRASIL, 2016).

Diante dessas mudanças trazidas pelo novo marco legal, observa-se a questão dos progressos nas legislações relacionadas ao incentivo à inovação, e os IFs fazem parte desse progresso tecnológico, pois a Lei n. 11.892/2008, no seu artigo $2^{\circ}$, conceitua essas ICTs públicas como uma "[...] edificação multicampi e pluricurricular que oferece educação profissional e tecnológica em diversos graus de ensino, vinculando o arcabouço técnico e tecnológico com a praxe pedagógica" (BRASIL, 2008, p. 1). Dessa forma, pode-se inferir que a Lei n. 11.892/2008 serviu de instrumento para disseminação dessas ICTs públicas em diversos Estados brasileiros para impulsionar a instituição de novas tecnologias que beneficiem a comunidade em variadas áreas do conhecimento.

Assim, os IFs têm um papel essencial no ecossistema de inovação nacional, isso porque essas instituições podem favorecer a sociedade por meio de espaços inovadores e voltados ao empreendedorismo, como também promove articulações com diversas entidades públicas ou privadas. Esses espaços, segundo consta no Decreto n. 9.283/2018, artigo $2^{\circ}$, inciso II, alínea a,

[...] agregam infraestrutura e arranjos institucionais e culturais, que atraem empreendedores e recursos financeiros, constituem lugares que potencializam o desenvolvimento da sociedade do conhecimento e compreendem, entre outros, parques científicos e tecnológicos, cidades inteligentes, distritos de inovação e polos tecnológicos. (BRASIL, 2018, p. 1)

1 "Innovation is a new or improved productor or process (or a combination thereof) that differs significantly from the unit's previous products or processes and hás been made available to potencial users (product) or brought use by the unit (process)". (OECD, 2018, p. 20) 
Destarte, requerem, portanto, uma gestão estratégia que contribua para o desenvolvimento científico e tecnológico nas regiões em que estão presentes, contribuindo para o crescimento da economia local, regional e nacional.

\subsection{O Planejamento Estratégico e sua Importância para o Desenvolvimento Tecnológico dos IFETS}

O planejamento estratégico consiste em um procedimento sistêmico de gestão voltado para definir os objetivos, as metas e os indicadores que nortearão as ações institucionais, os quais devem conduzir a instituição no cumprimento de sua missão (REZENDE, 2008). Para tanto, essa ferramenta necessita do integral envolvimento dos atores da instituição, das variáveis do ambiente externo que interferem na organização, sendo que, para a sua elaboração, requer o uso de variadas e complementares técnicas administrativas.

Assim, o planejamento estratégico observa uma instituição sob diversos delineamentos, visando a definir os caminhos a serem percorridos, deixando suscetível o acompanhamento $e$ a averiguação de suas ações realizadas. Esse planejamento é norteado por vários princípios metodológicos que delimitam o trabalho dos profissionais envolvidos, sendo que esses trabalhadores são comprometidos a estabelecer o direcionamento da organização (GUERREIRO, 2018; OLIVEIRA, 2014).

Para elaborar e implementar o planejamento estratégico, é preciso realizar preliminarmente um diagnóstico estratégico do ambiente e analisar os pontos fortes e fracos para identificar o que precisa ser modificado e poder atingir as metas programadas. Assim, a Matriz FOFA (SOWT), que é estruturada pelas Forças, Oportunidades, Fraquezas e Ameaças e pode ser representada, respectivamente, no inglês por Matriz SWOT (Strengths, Weaknesses, Opportunities and Threats), é uma das metodologias utilizadas para a construção do planejamento institucional. Esse instrumento faz parte do planejamento e gestão, pois proporciona a evidência - das Forças e Oportunidades - considerando os pontos fortes, bem como as suas fragilidades que são pontos fracos - Fraquezas e Ameaças (GOMIDE et al., 2015). Essa Matriz compõe a fase inicial da estruturação do planejamento estratégico que visa a definir estratégias vindouras eficazes para uma instituição (FANTONI et al., 2016; FERREIRA et al., 2019).

Dessa forma, para encontrar os fatores do ambiente organizacional, pode-se estudar as áreas operacionais e realizar um estudo da evolução do desempenho do estabelecimento $e$ benchmarking que oferece a instituição uma base das boas práticas administrativas de outros Órgãos (MAXIMIANO, 2000). A análise estratégica do ambiente organizacional utilizando a ferramenta Matriz SWOT tem grande importância na estruturação do planejamento estratégico, porque busca verificar a atual situação da empresa por meio da identificação de determinantes do ambiente que influenciam no status do processo administrativo da instituição.

Com o crescimento das tecnologias e o surgimento de novas inovações, os IFs precisam utilizar o planejamento estratégico a fim de direcionar as suas ações a um determinado objetivo, visando a alcançar os resultados esperados em diversos setores da empresa, seja na área administrativa, financeira, gestão de pessoas, de marketing, entre outras. Essa visão holística da instituição auxilia na verificação dos setores que carecem de aprimoramento para a maximização das atividades executadas. Em vista disso, as pessoas envolvidas na elaboração desse planejamento devem estar motivadas e comprometidas para atingir os melhores resultados. 
O planejamento estratégico tem fundamental importância para a condução das IFs, uma vez que direciona essas ICTs públicas a cumprir os seus objetivos descritos na Lei n. 11.892/2008, destacando-se o artigo $6^{\circ}$, inciso VIII, referente ao estímulo à pesquisa aplicada, à realização de projeto empreendedor, cultural, cooperativo e ao desenvolvimento científico e tecnológico (BRASIL, 2008). Isso, porque, os IFs têm um papel essencial na indução da produção tecnológica global. Amorim (2019) reforça os pontos que favorecem essa indução para a sociedade, tendo como benefícios a atenuação dos impactos sociais, o progresso dos bens e serviços, a potencialização dos recursos e a formação de valor para a economia mundial.

Assim, no âmbito das ICTs públicas, a exemplo dos IFs, o planejamento estratégico servirá de alicerce para atingir a reorganização prescrita em Lei (GUERREIRO, 2018), contribuindo para que estes possam fortificar o desenvolvimento científico, a indução da produção tecnológica e a transferência de tecnologia no setor produtivo.

\section{Metodologia}

A metodologia é dividida em três tópicos, Unidade de Análise representada pela composição do objeto de estudo e Caracterização da Pesquisa, nesta seção são descritos os procedimentos metodológicos utilizados com o propósito de alcançar o objetivo proposto e o último tópico (Etapas, Procedimentos e Estratégia Metodológica) demonstra as etapas realizadas nesta pesquisa visando à construção do trabalho.

\subsection{Unidade de Análise}

A unidade de análise da pesquisa foi o NIT do IF Baiano. O IF Baiano é composto de antigas Escolas Agrotécnicas Federais e de Escolas Médias de Agropecuária Regionais da Comissão Executiva do Plano da Lavoura Cacaueira (CEPLAC) - EMARC, presentes no Estado da Bahia. Em virtude disso, foi investigado o período compreendido entre 2015 e 2019, corte temporal referente aos documentos oficiais do IF Baiano.

\subsection{Caracterização da Pesquisa}

Para o alcance do objetivo proposto nesta pesquisa, realizou-se um levantamento bibliográfico, exploratório (VERGARA, 2016), utilizando-se de coleta de dados em artigos científicos, manuais, livros, entre outros, cuja abordagem aplicada foi a qualitativa, descritiva. Ademais, utilizou-se da Matriz FOFA para se ter o diagnóstico da instituição com o intuito de proporcionar visibilidade de pontos e de processos que precisam ser melhorados, identificando, assim, fatores que interferem no NIT do IF Baiano, que podem virar oportunidade para criar espaços inovadores. Por sua vez, fez-se também uma pesquisa documental para coleta dos dados secundários por meio da busca de informações em documentos oficiais no site da instituição. Para a pesquisa documental, foram verificados os documentos oficiais do IF Baiano, como: Plano de Desenvolvimento Institucional (PDI), Relatório de Gestão 2018, Projeto Político Pedagógico Institucional (PPPI), Regimento Geral, Estatuto e o Regimento Interno do NIT. 


\subsection{Etapas, Procedimento e Estratégia Metodológica}

O artigo apresentado foi realizado em quatro etapas. A primeira etapa compreende a pesquisa exploratória empregando o levantamento documental, por meio da consulta aos Websites do IF Baiano, artigos científicos nacionais, monografias, dissertações, relatórios técnicos, legislações e manual internacional. Nessa etapa, houve a coleta de informações em documentos oficiais da instituição direcionadas ao fomento da inovação.

Na segunda etapa, foram utilizados os dados da coleta de documentos oficiais no sítio eletrônico do IF Baiano para construção da Matriz FOFA do NIT/IF Baiano para identificação das forças, oportunidades, fraquezas e ameaças do setor, o que aborda as pesquisas científicas $e$ as inovações tecnológicas remetidas ao Núcleo.

Em relação à terceira etapa, houve a análise estratégica dos dados da Matriz FOFA em face do Novo Marco Legal da CT\&I e comparação dos dados das metas intermediárias (número de projetos de pesquisas realizadas) com os números desses projetos realizados pelo IF Baiano. Esses dados são relacionados ao objetivo estratégico (fortalecer e ampliar as ações de pesquisa, inovação e pós-graduação) do período de 2015 a 2018, como também foram evidenciados dados dos quantitativos de depósito dos pedidos de patentes por meio de busca avançada na base de dados do Instituto Nacional da Propriedade Industrial (INPI), para tanto, foi introduzido no campo depositante o número do Cadastro Nacional da Pessoa Jurídica (CNPJ) do IF Baiano. Ainda nesta etapa foi possível verificar os fatores internos e externos do setor NIT/IF Baiano, demonstrando suas forças, oportunidades, fraquezas e ameaças e relacionando-as com o Novo Marco Legal da CT\&I, conseguindo alcançar o objetivo da pesquisa.

Na última etapa, a fim de que os dados obtidos a partir da matriz de SWOT pudessem ser validados, realizou-se o envio do relatório com o diagnóstico para que a gestão do NIT analisasse os resultados. O envio ocorreu por e-mail em 27 de abril de 2020 e, após validação das informações, cujo retorno foi obtido em 11 de maio de 2020, as análises foram finalizadas, sendo esta etapa de fundamental importância, tanto para as análises quanto para as considerações finais.

\section{Resultados e Discussão}

Conforme já destacado, a Lei n. 11.892/08 estabeleceu os Institutos Federais de educação de ensino superior, básica e profissional, pluricurriculares e multicampi, em que disponibiliza educação profissional e tecnológica nas diversas áreas (BRASIL, 2008), surgindo a partir disso o IF Baiano. Atualmente, essa instituição tem um total de 14 Campi espalhados em diversos municípios no Estado da Bahia, localizados nas cidades de Catu, Senhor do Bonfim, Santa Inês, Guanambi, Valença, Teixeira de Freitas, Itapetinga, Uruçuca, Bom Jesus da Lapa, Governador Mangabeira, Serrinha, Alagoinhas, Itaberaba e Xique-Xique. Além disso, a instituição conta também com 14 polos de educação a distância, uma Reitoria e um Centro de Referência com estruturas localizadas em Salvador (IF BAIANO, 2019b).

O IF Baiano possui autonomia didático-científica, administrativa, financeira e patrimonial. A instituição oferta Ensino Médio e Superior direcionado à educação Profissional e Tecnoló- 
gica. Essa organização proporciona à comunidade o tripé: ensino, pesquisa e extensão, eixos voltados para o mercado de trabalho, ofertando cursos técnicos - integrados, subsequentes na modalidade presencial ou a distância, Proeja, graduação, pós-graduação e cursos de capacitação oferecidos por meio de Programas de Extensão. Desse modo, o IF Baiano disponibiliza à sociedade educação pública de qualidade, aberta para todos os cidadãos, atuando em diferentes áreas e territórios da Bahia (IF BAIANO, 2019b).

Vale ressaltar que, nesse processo, o NIT tem papel fundamental para a gestão da propriedade intelectual do Instituto, transferência da tecnologia para sociedade promover a inovação. Diante disso, as atividades organizacionais a serem implementadas pelas ICTs deveriam considerar a criação desse setor em um sistema que dispõe de relações dinâmicas. Nesse sentido, essas ações devem fundamentar em bases conceituais de gestão estratégica e necessitam alinhar-se com estratégias direcionadas à tecnologia e à inovação da instituição, visando a contribuir no progresso ou no ajuste dessas atividades (ANDRADE et al., 2018).

\subsection{O Núcleo de Inovação Tecnológica do IF Baiano}

Conforme aponta o organograma do IF Baiano, que se encontra em alteração, o NIT está interligado com a Pró-Reitoria de Pesquisa e Inovação (PROPES). De acordo com o Relatório de Gestão (IF BAIANO, 2018, p. 7), "[...] os Regimentos internos da Reitoria e dos Campi estão em fase de análise e de reestruturação para que sejam consolidados no Regimento Geral do Instituto". Esse Núcleo foi regulamentado pela Resolução/CONSUP n. 35, de $1^{\circ}$ de setembro de 2016 (IF BAIANO, 2016b), que trata do Regimento Interno do NIT/IF Baiano, sendo um setor que tem a cooperação de docentes, discentes, pesquisadores e de profissionais que atuam com a Propriedade Intelectual para o fomento à inovação tecnológica (IF BAIANO, 2019d).

Segundo o Projeto Político Pedagógico Institucional (PPPI) do IF Baiano, a PROPES é um órgão que assessora a Reitoria e tem como atribuições planejar, coordenar e acompanhar as atividades ligadas ao alargamento da pesquisa e da inovação, definindo diretrizes para o planejamento e o desempenho dessas atividades (IF BAIANO, 2014b; 2019e). Destarte, o NIT/ IF Baiano tem a responsabilidade de gerir a política de inovação tecnológica e de proteger o conhecimento motivado pela instituição, além de, também, apoiar as ações de inovação relativas à proteção da propriedade Intelectual. Vale ressaltar que não foi verificada a existência da política de inovação do IF Baiano até o fechamento da presente pesquisa (grifo nosso), o que reforça a contribuição prática da presente pesquisa.

Conforme prevê o Regimento Interno do NIT do IF Baiano (2016a, p. 1), entre as atribuições que competem a esse setor, destacam-se: "I - estabelecer uma política de propriedade intelectual e de inovação tecnológica; [...] e VI - fomentar e fortalecer parcerias do IF Baiano com órgãos governamentais, empresas e sociedade, para a difusão de novas tecnologias". Assim, percebe-se que o NIT/IF Baiano exerce atividades seguindo as normas da Lei de Propriedade Industrial, que visa à proteção dos direitos à propriedade Industrial, levando em consideração a impulsão da economia e a inovação tecnológica regional, local e, consequentemente, nacional. Assim, esse setor tem como objetivo intermediar e gerir a política de inovação por meio de ações voltadas à transferência de tecnologia com diversificadas instituições. 


\subsection{Análise das Forças, Oportunidades, Fraquezas e Ameaças (Matriz FOFA) do NIT/IF Baiano}

A análise da Matriz FOFA do NIT/IF Baiano representa um instrumento que agrega no crescimento da instituição para o alcance dos objetivos estratégicos, por isso Fantoni et al. (2016, p. 2) reforçam que "[...] diante do surgimento de novas tecnologias e com um mercado em constante transformação, as organizações buscam estratégias que os diferenciem dos concorrentes e gerem vantagens competitivas". No Quadro 1, representado pela Matriz FOFA, é possível observar os aspectos positivos e negativos referentes ao NIT/IF Baiano.

\begin{tabular}{|c|c|c|}
\hline & ASPECTOS POSITIVOS & ASPECTOS NEGATIVOS \\
\hline 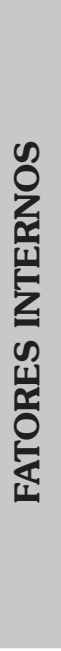 & 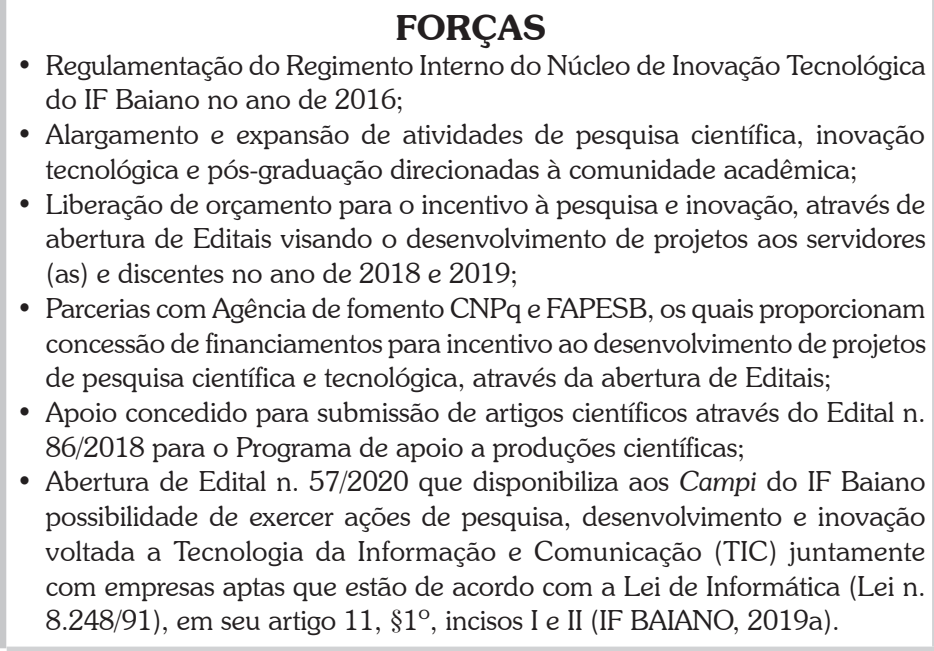 & $\begin{array}{l}\text { FRAQUEZAS } \\
\text { - Baixo número de profissionais para compor } \\
\text { - NIT/IF Baiano; } \\
\text { - Ausência, até o fechamento da pesquisa, de } \\
\text { uma política de inovação institucional; } \\
\text { - Ausência de transferência de tecnologia; } \\
\text { - O IF Baiano ainda não tem patentes } \\
\text { concedidas, conta com dezesseis (18) registros } \\
\text { de depósito junto ao INPI; } \\
\text { - Inexistência de contratos de negociação e } \\
\text { transferência de tecnologia. } \\
\text { - Cultura organizacional. }\end{array}$ \\
\hline 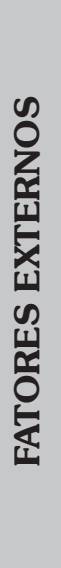 & $\begin{array}{l}\text { OPORTUNIDADES } \\
\text { - Novo Marco Legal da CT\&I (Lei n. 13.243/2016) regulamentado pelo Decreto } \\
\text { no. 9.283/2018 fortalecendo NIT/IF Baiano; } \\
\text { - Concursos públicos do IF Baiano } 2019 \text { para docente e técnico administrativo } \\
\text { em educação em andamento, que poderá contribuir principalmente para } \\
\text { ampliação do quadro de pessoal da instituição e, em particular, do NIT; } \\
\text { - Abertura de editais direcionados para Inovação Tecnológica; } \\
\text { - Ampliação de ações a inovação devido à aquisição de } 50 \text { cotas liberadas } \\
\text { para o acesso ao Sistema Financiar que oferece aos pesquisadores, à } \\
\text { comunidade acadêmica e aos empresários informações mundiais de Agências } \\
\text { financiadoras de projetos de pesquisa, desenvolvimento e inovação; } \\
\text { - Construir manuais e procedimentos internos de apoio à negociação e } \\
\text { transferência de tecnologia; } \\
\text { - Estabelecer parcerias com instituições do setor produtivo para o } \\
\text { desenvolvimento de pesquisa tecnológica aplicada para impulsionar a área } \\
\text { agrotécnica, industrial e viabilizar a transferência de tecnologia. }\end{array}$ & $\begin{array}{l}\text { AMEAÇAS } \\
\text { - Eventual modificação de Política de Governo, } \\
\text { voltado para a rede federal de ensino básico, } \\
\text { técnico e tecnológico, Universidades Federais } \\
\text { de ensino e Institutos de Pesquisa; } \\
\text { - Cortes atuais e futuros de verbas nas } \\
\text { Instituições Federais afetando o orçamento; } \\
\text { - Possível falta de alinhamento entre a produção } \\
\text { científica e tecnológica aplicada e a missão } \\
\text { institucional em função da ausência de política } \\
\text { de inovação. }\end{array}$ \\
\hline
\end{tabular}

Fonte: Elaborado pelos autores deste artigo (2020)

A partir do que foi apresentado no Quadro 1, nota-se que os fatores positivos se relacionam com o incremento e o fortalecimento das ações direcionadas à pesquisa, extensão e inovação no NIT/IF Baiano. Essas práticas exercem caráter educativo e investigativo para elaboração de resoluções tecnológicas a favor da sociedade, acarretando o cumprimento do desenvolvimento econômico e social. Isso pode ser reforçado, devido ao fato de "[...] países de industrialização tardia exitosa tiveram suas estratégias assentadas em inflexões decisivas no contexto da educação e da ciência e tecnologia" (BRASIL, 2016b, p. 7), sendo que esse tripé é essencial para atingir resultados promissores para impulsionar a inovação tecnológica. 
Com a institucionalização de Programas de estímulo aos discentes pela PROPES, que incentiva novos talentos com a prática do empreendedorismo, de inovação e desenvolvimento tecnológico, de oferta de cursos de pós-graduação (Lato Sensu e Stricto Sensu), o IF Baiano visa à maximização de difusão do conhecimento e de fomento à pesquisa científica. Percebe-se que essa prática do IF Baiano tem o intuito de estreitar seu objetivo institucional que vem de encontro com a Lei n. 11.892/2008, artigo 7º IV, ao desenvolver atividades de extensão direcionadas à educação profissional e tecnológica, voltadas para a qualificação profissional e social com proeminência na produção e propagação do conhecimento científico e tecnológico (BRASIL, 2008).

Guerreiro (2018) salienta que a variável financeira é um fator importante para a viabilização e conservação organizacional e que os órgãos públicos devem atentar para a otimização da utilização dessa verba. Assim, esse ponto estratégico referente à captação e aplicação de recursos é destinado para robustecer fontes orçamentárias existentes, aprimorar a captação de receitas, bem como criar ativos e aperfeiçoar os gastos públicos direcionados à inovação para sua melhor efetividade.

Dessa forma, por meio do PDI do IF Baiano, é possível observar os indicadores intermediários dos projetos de pesquisa e inovações tecnológicas/patentes referentes ao Objetivo Estratégico Fortalecer e ampliar as ações de pesquisa, inovação e pós-graduação, das metas intermediárias de 2015 a 2019. Assim, verificou-se que o indicador intermediário - Número total de projetos de pesquisa realizados - alcançou a meta de 58 projetos em 2015, sendo adicionados 16 projetos a cada ano, visando a atingir em 2018 um total de 104 projetos (IF BAIANO, 2014a). Com isso, nota-se no Relatório de Gestão da instituição um fortalecimento desse indicador, pois houve aumento significativo no número de projetos de pesquisa desenvolvidos em 2016, em comparação à meta intermediária de 74 projetos, atingindo um total de 321 projetos. Já nos anos posteriores, os projetos desenvolvidos tiveram queda no quantitativo, mas ultrapassaram a meta intermediária estipulada, totalizando, respectivamente, em 2017 e 2018 - 190 e 180 projetos realizados (IF BAIANO, 2018).

O Ministério da Ciência, Tecnologia, Inovações e Comunicações (MCTIC) informa que as bolsas científicas beneficiam a interação dos institutos de ensino-empresa, sendo designadas para a inclusão de pesquisadores no sistema produtivo para a realização de atividades e projetos de Pesquisa, Desenvolvimento e Inovação (PD\&I) e na habilitação do discente a diferentes temáticas direcionados à inovação e tecnologia. As bolsas são concedidas a pesquisadores em ICTs e empresas (BRASIL, 2016b).

Ao analisar o PDI 2015-2019 e o Relatório de Gestão do IF Baiano, observa-se uma evolução da atividade científica pautada em conhecimento e voltada para o desenvolvimento social, o qual ultrapassou as metas programadas. Guerreiro (2018) ressalta que a análise da Matriz FOFA, juntamente com os objetivos estratégicos de inovação e seus indicadores e metas intermediárias corroboram para explicitar os pontos que podem ser melhorados, e apontam as oportunidades e ameaças que podem afetar o Órgão.

Em referência ao indicador - Número de inovações tecnológicas patentes, as metas intermediárias previstas em 2018 e 2019 foram respectivamente três e 12 depósitos de patentes, e nos anos anteriores não tiveram previsão de metas. Dessa forma, por meio do mapeamento de patente na base de dados do INPI, verificou-se que o IF Baiano em 2015 teve cinco depósitos de pedidos de patentes, seguido em 2016 de sete de depósitos de patentes, um número expressivo 
em relação aos outros anos. Já em 2018, a instituição atingiu quatro depósitos de pedido de patente, totalizando em cinco anos, 18 depósitos de pedidos de patentes.

Assim, observa-se que o quantitativo de registro de patentes do IF Baiano junto ao Instituto INPI no período de 2015 a 2018 ultrapassou a meta intermediária prevista pela Instituição, com exceção em 2019 que resultou em dois pedido de patente. Desse modo, as propriedades intelectuais promovem meios para que essas inovações provenientes das atividades científicas da comunidade acadêmica agreguem valor à organização que notadamente beneficie a sociedade. A lei de Propriedade Industrial (LPI) ressalta a proteção dos bens intangíveis, sendo a patente uma delas, desse modo, deve considerar "[...] o seu interesse social e o desenvolvimento tecnológico e econômico do país [...]", mediante o artigo $2^{\circ}$, inciso I, da referida Lei, "[...] concessão de patentes de invenção e de modelo de utilidade" (BRASIL, 1996, p. 1). Nesse contexto, a inovação é essencial para alavancar os indicadores tecnológicos e de pesquisas científicas. Com isso, pode-se observar que o IF Baiano tem como fraqueza a cultura organizacional de inovação, que está muito ligada à submissão de projetos e aos editais internos, não tendo uma visão de transformação do desenvolvimento regional, local e da instituição como um todo.

Cumpre destacar que, a partir de 2016, o IF Baiano passou a realizar um maior investimento em atividades de pesquisa e de pós-graduação para desenvolvimento de projetos, atividades nas quais se pode apontar como elemento propulsor a regulamentação do NIT/IF Baiano e o fortalecimento da Lei de Inovação, que juntos representam uma oportunidade para o estímulo à comunidade acadêmica na ampliação da pesquisa científica e tecnológica. Amorim (2019) descreve que as legislações da inovação, bem como o Novo Marco Legal da CT\&I são dispositivos propulsores para o desenvolvimento econômico baseado em inovação e conhecimento científico e tecnológico, tornando-se ferramentas estratégicas para o país. Assim, tais instrumentos tornam-se oportunos para o crescimento do NIT/IF Baiano, pois podem proporcionar o surgimento de parcerias, convênios e transferência de tecnologia para o desenvolvimento da instituição. Dessa forma, tem-se como fator preponderante e essencial a construção da Política de Inovação, que tem a finalidade de propor diretrizes para o fomento à inovação tecnológica na condução de programas de incentivo à inovação.

Entretanto, no Relatório de Gestão (IF BAIANO, 2018), encontra-se outra oportunidade importante para ampliar a pesquisa científica e de inovação que é o Sistema Financiar, instrumento que disponibiliza informações mundiais de agências financiadoras de projetos de pesquisa, desenvolvimento e inovação aos pesquisadores e interessados. Com isso, o IF Baiano adquiriu 50 cotas de acesso para comunidade acadêmica, entre pesquisadores, gestores $e$ docentes para realização de buscas sobre fontes financiadoras (IF BAIANO, 2018; 2019c). Além disso, o fomento à pesquisa das agências do Conselho Nacional de Desenvolvimento Científico e Tecnológico (CNPq) e da Fundação de Amparo à Pesquisa do Estado da Bahia (FAPESB) a estudantes do ensino médio técnico e da graduação integradas tem como intuito incentivar a pesquisa científica (IF BAIANO, 2019c).

Percebe-se também que a abertura do edital do Concurso do IF Baiano 2019 contribuiu para que ocorra um aumento no quadro de pessoal da organização, o que pode favorecer a ampliação do número de servidores do NIT/IF Baiano, que atualmente encontra-se limitado em termos quantitativos. Desse modo, cabe destacar que o quadro de profissionais NIT/IF Baiano ainda sofre por falta de pessoal e de capacitação profissional, isso porque o NIT é constituído por uma servidora vinculada ao Pró-Reitor da PROPES. Diante disso, deve-se atentar para a 
captura de mais recursos humanos para o setor, levando-se em consideração o Novo Marco Legal da CT\&I.

Cabe destacar que, segundo Andrade et al. (2018), a gestão desse setor deve seguir processos pautados em uma gestão estratégica. Entretanto, a formulação da política de inovação é de grande importância para fortalecimento do IF Baiano, por meio de seu NIT, pois contribui para o fomento da pesquisa direcionada à inovação tecnológica, à gestão eficiente dos ativos intangíveis, à transferência de tecnologia nos diversos entes federativos, além de induzir ações voltadas para o empreendedorismo, a criação de espaços inovadores, a capacitação tecnológica, entre outras atividades atribuídas pelo Novo Marco Legal da CT\&I.

Então, observa-se com a análise estratégica do NIT/IF Baiano que o setor está aos poucos caminhando para atingir o status de autonomia tecnológica, apesar de ter apenas três anos de instituído. O IF Baiano conta com a Resolução n. 31 de novembro de 2015, que "[...] dispõe sobre a estrutura e atribuições da Coordenação de Pesquisa nos Campi do IF Baiano [...]" (IF BAIANO, 2015, p. 1), relacionadas às atividades de pesquisa e inovação nos Campi espalhados no interior da Bahia. Assim, o IF Baiano precisa utilizar-se de estratégias eficazes e sob a ótica do Novo Marco Legal da CT\&I para munir-se de ferramentas a fim de atingir seus objetivos institucionais. Segundo Andrade et al. (2018), as competências do NIT atribuídas pelo Novo Marco Legal da CT\&I é estratégica devido à política de inovação e às políticas operacionais, no que refere a atividades de sustentação para ações cotidianas. Portanto, mesmo em observância a essas competências, a análise do NIT mostra que esse setor requer estímulo de suas habilidades organizacionais para aperfeiçoar a sua função, visando ao estabelecimento de estratégias de gestão da inovação na ICT.

Outrossim, a mudança política de Governo é um fator externo que pode causar impacto negativo à instituição, pois pode desestruturar os objetivos estratégicos programados afetando o cumprimento de suas metas em um determinado período. O Novo Marco Legal da CT\&I evidencia no seu artigo $2^{\circ}$, inciso II, que a instituição deve estabelecer medidas de estímulo para inovação e a pesquisa científica e tecnológica por meio da "[...] promoção e continuidade dos processos de desenvolvimento científico, tecnológico e de inovação, assegurados os recursos humanos, econômicos e financeiros para tal finalidade" (BRASIL, 2016, p. 1). Outro elemento que pode ser considerado ameaça são os cortes de recursos financeiros devido à contenção de gastos públicos nas organizações de ensino, em virtude da nova conjuntura vivenciada requerendo um olhar estratégico para o gestor da instituição na alocação desses recursos.

\section{Considerações Finais}

A pesquisa analisou as forças, oportunidades, fraquezas e ameaças relacionadas ao Núcleo de Inovação Tecnológica do Instituto Federal Baiano (NIT/IF Baiano), em face do contexto trazido pelo Novo Marco Legal da Ciência, Tecnologia e Inovação (CT\&I) instituído pela Lei n. 13.243/2016. Para tanto, foi realizada uma pesquisa com uma abordagem qualitativa, descritiva, de natureza bibliográfica e documental.

Dessa forma, observou-se como força a regulamentação do NIT/IF Baiano criado para auxiliar nas implementações de ações voltadas para o avanço da pesquisa científica e tecnológica, impulsionando a liberação de orçamento interno à inovação. O NIT/IF Baiano teve como 
oportunidade essencial o Novo Marco Legal da CT\&I que trouxe possibilidades de um maior engajamento das ICTs com o setor produtivo, sendo que, a partir deste, perspectivas de parcerias vêm sendo prospectadas para a integração de espaços inovadores para o incentivo à pesquisa aplicada na área agrotécnica e industrial.

Com relação às fraquezas do NIT/IF Baiano, destaca-se o baixo número de profissionais que compõem esse Núcleo, sendo que o Concurso Público do IF Baiano 2019 pode favorecer a estruturação do setor. Outra fraqueza a relatar é a ausência de Política de Inovação para direcionar e fomentar a transferência de tecnologia e os processos de negociação com o setor produtivo. Entretanto, como ameaças, observou-se a eventual mudança de Política de Governo na rede federal de ensino e a instabilidade orçamentária.

Conclui-se acerca dos dados identificados na análise estratégica do NIT/IF Baiano que, atualmente, o setor está de acordo com as legislações da inovação em relação à regulamentação do Núcleo de Inovação, sendo que precisa implementar ações estratégicas para NIT/IF Baiano no contexto do Novo Marco Legal da CT\&I, por meio do planejamento estratégico e da Política de Inovação institucional.

Por fim, recomenda-se como pesquisas futuras a realização de um estudo de caso no NIT/ IF Baiano, a fim de aprofundar os estudos acerca do objeto analisado, que contribua para a formulação da política de inovação institucional e seu alinhamento com o Novo Marco Legal da CT\&I, tendo o propósito de induzir o desenvolvimento científico e tecnológico institucional com o intuito de fomentar a transferência de tecnologia e as redes de interação com atores do setor produtivo.

\section{Referências}

AMORIM, Viviane Peneluca. Análise das políticas de inovação dos Institutos Federais de Educação Ciência e Tecnológica (IFETs) da região Nordeste: um estudo exploratório. 2019. 51f. Monografia (Graduação em Administração) - Instituto Federal de Educação, Ciência e Tecnologia da Bahia, Salvador, 2019.

ANDRADE. Herlandí de Souza et al. A necessidade de inovação nos processos dos Núcleos de Inovação Tecnológica. In: ANDRADE, de Souza Herlandí; TORKOMIAN, Ana Lúcia Vitale; JÚNIOR, Milton de Freitas Chagas (org.). Boas práticas de Gestão nos Núcleos de Inovação Tecnológica: Experiência Inovadora. São Paulo: Edições Brasil, 2018. p. 11-19.

BAGNATO, Vanderley Salvador; ORTEGA, Luciane Maneguin; MARCOLAN, Daniel. Guia Prático II - Transferência de Tecnologia: parcerias entre universidade e empresa. São Paulo: Agência USP de Inovação, 2016. Disponível em: http://www.inovacao.usp.br/wp-content/uploads/ sites/300/2017/10/cartilha_TT_bom.pdf. Acesso em: 22 set. 2019.

BRASIL. Lei n. 9.279, de 14 de maio de 1996. Regula os direitos e obrigações relacionadas à propriedade industrial. Brasília, DF: Presidência da República, [1996]. Disponível em: http://www. planalto.gov.br/ccivil_03/Leis/L9279.htm. Acesso em: 26 set. 2019.

BRASIL. Lei n. 10.973, de 2 de dezembro de 2004. Dispõe sobre incentivos à inovação e à pesquisa científica e tecnológica no ambiente produtivo e dá outras providências. Brasília, DF: Presidência da República, [2004]. Disponível em: http://www.planalto.gov.br/ccivil_03/_ato20042006/2004/lei/l10.973.htm. Acesso em: 15 ago. 2019. 
BRASIL. Lei n. 11.892, de 29 de dezembro de 2008. Institui a Rede Federal de Educação Profissional, Científica e Tecnológica, cria os Institutos Federais de Educação, Ciência e Tecnologia, e dá outras providências. Brasília, DF: Presidência da República, [2008]. Disponível em: http://www. planalto.gov.br/ccivil_03/_Ato2007-2010/2008/Lei/L11892.htm. Acesso em: 13 ago. 2019.

BRASIL. Lei n. 13.243, de 11 de janeiro de 2016. Dispõe sobre estímulos ao desenvolvimento científico, à pesquisa, à capacitação científica e tecnológica e à inovação [...]. Brasília, DF: Presidência da República, [2016a]. Disponível em: http://www.planalto.gov.br/ccivil_03/_Ato20152018/2016/Lei/L13243.htm. Acesso em: 22 set. 2019.

BRASIL. Ministério da Ciência, Tecnologia, Inovações e Comunicações. Estratégia nacional de ciência, tecnologia e inovação 2016/2022: ciência, tecnologia e inovação para o desenvolvimento econômico e social. Brasília, DF: Ministério da Ciência, Tecnologia, Inovações e Comunicações. [2016b]. Disponível em: http:/www.finep.gov.br/images/a-finep/ Politica/16_03_2018_Estrategia_Nacional_de_Ciencia_Tecnologia_e_Inovacao_2016_2022.pdf. Acesso em: 4 ago. 2019.

BRASIL. Decreto n. 9.283, de 7 de fevereiro de 2018. Regulamenta a Lei n. 10.973, de 2 de dezembro de 2004, a Lei n. 13.243, de 11 de janeiro de 2016, o art. 24, $\S 3^{\circ}$, e o art. 32, § $7^{\circ}$, da Lei n. 8.666, de 21 de junho de 1993 [...]. Brasília, DF: Presidência da República, [2018]. Disponível em: http:/www.planalto.gov.br/ccivil_03/_ato2015-2018/2018/decreto/d9283.htm. Acesso em: 31 jun. 2019.

FANTONI, Bruna Barbosa et al. Aplicação do Modelo de Porter e Análise Swot no Diagnóstico Estratégico de uma Empresa de Construção Civil. In: CONGRESSO NACIONAL DE EXCELÊNCIA EM GESTÃO, 12. INOVARSE, 3., 2016, Rio de Janeiro. Anais [...]. Rio de Janeiro: Universidade Federal Fluminense, 2016. p. 1-14. Disponível em: http://www.inovarse.org/sites/default/files/ T16_271.pdf. Acesso em: 4 set. 2019

FERNANDES, Djair Roberto. Uma visão sobre a análise da matriz SWOT como ferramenta para elaboração da estratégia. UNOPAR Científica, Ciências Jurídicas e Empresariais, Londrina, v. 13, n. 2, p. 57-68, set. 2012. Disponível em: file:///C:/Users/Mestre/Downloads/720-Texto\%20do\%20 artigo-2832-1-10-20150702\%20(1).pdf. Acesso em: 23 set. 2019.

FERREIRA, Evelice Pereira et al. Gestão estratégica em frigoríficos: aplicação da análise SWOT na etapa de armazenagem e expedição. Gestão \& Produção, São Carlos, v. 26, n. 2, p. 1-14, 2019. DOI: https://doi.org/10.1590/0104-530X-3147-19. Disponível em: http://www.scielo.br/pdf/gp/ v26n2/0104-530X-gp-26-2-e3147.pdf. Acesso em: 14 set. 2019.

GOMIDE, Márcia et al. Fortalezas, Oportunidades, Fraquezas e Ameaças (Matriz FOFA) de uma Comunidade Ribeirinha Sul-Amazônica na perspectiva da Análise de Redes Sociais: aportes para a Atenção Básica à Saúde. Cad. Saúde Colet., Rio de Janeiro, v. 23, n. 3, p. 222-230, 2015. DOI: 10.1590/1414-462X201500030089. Disponível em: file://C:/Users/Mestre/Downloads/Fortalezas Oportunidades_Fraquezas_e_Ameacas_Matri.pdf. Acesso em: 18 nov. 2019.

GUERREIRO, Evelyn Seilhe. Proposta de Planejamento Estratégico para o Departamento de inovação (DINOV) do IFBA considerando o novo Marco Regulatório de Inovação. 2018. 94f. Relatório Técnico (Mestrado em Propriedade Intelectual e Transferência de Tecnologia para a inovação) - Instituto Federal de Educação, Ciência e Tecnologia da Bahia, Salvador, 2018.

IF BAIANO - INSTITUTO FEDERAL DE EDUCAÇÃO, CIÊNCIA E TECNOLOGIA BAIANO. Edital n. 57 de 20 de abril de 2020. Salvador: IF Baiano, 2019a. Disponível em: https://concurso. ifbaiano.edu.br/portal/chamada-propes-02-abril-2020/wp-content/uploads/sites/335/2020/04/Editaln\%C2\%BA-57-de-20-de-abril-de-2020.pdf. Acesso em: 7 maio 2020. 
IF BAIANO - INSTITUTO FEDERAL DE EDUCAÇÃO, CIÊNCIA E TECNOLOGIA BAIANO.

Estatuto Instituto Federal de Educação Ciência e Tecnologia Baiano. Salvador: IF Baiano, 2019b. Disponível em: http://ifBaiano.edu.br/portal/wp-content/uploads/2019/05/Estatuto-do-IFBaiano_-Anexo-Resolu\%C3\%A7\%C3\%A3o-n\%C2\%BA-33.2019.pdf. Acesso em: 3 ago. 2019.

IF BAIANO - INSTITUTO FEDERAL DE EDUCAÇÃO, CIÊNCIA E TECNOLOGIA BAIANO. Infográficos 2015-2018. Salvador: IF Baiano, 2019c. Disponível em: http://ifBaiano.edu.br/portal/ pesquisa/plano-de-dados-abertos/. Acesso em: 15 ago. 2019.

IF BAIANO - INSTITUTO FEDERAL DE EDUCAÇÃO, CIÊNCIA E TECNOLOGIA BAIANO. Núcleo de Inovação Tecnológica. Salvador: IF Baiano, 2019d. Disponível em: http://ifBaiano.edu.br/ portal/nucleo-inovacao-tecnologica/. Acesso em: 24 set. 2019.

IF BAIANO - INSTITUTO FEDERAL DE EDUCAÇÃO, CIÊNCIA E TECNOLOGIA BAIANO. Plano de Desenvolvimento Institucional do Instituto Federal Baiano 2015-2019. Salvador: IF Baiano, 2014a. Disponível em: http://ifBaiano.edu.br/portal/wp-content/uploads/2015/12/pdi-20152019-versao-2018.pdf. Acesso em: 3 ago. 2019.

IF BAIANO - INSTITUTO FEDERAL DE EDUCAÇÃO, CIÊNCIA E TECNOLOGIA BAIANO. Projeto Pedagógico Político Institucional do IF BAIANO. Salvador: IF Baiano, 2014b. Disponível em: http://www.ifBaiano.edu.br/unidades/santaines/files/2017/07/4.-Projeto-Pol\%C3\%ADticoPedag\%C3\%B3gico-Institucional-PPPI.pdf. Acesso em: 3 ago. 2019.

IF BAIANO - INSTITUTO FEDERAL DE EDUCAÇÃO, CIÊNCIA E TECNOLOGIA BAIANO. Regimento Geral do Instituto Federal Baiano. Salvador: IF Baiano, 2019e. Disponível em: http:// ifBaiano.edu.br/portal/wp-content/uploads/2019/07/Regimento-Geral-do-IF-Baiano-Final-2019.pdf. Acesso em: 3 ago. 2019.

IF BAIANO - INSTITUTO FEDERAL DE EDUCAÇÃO, CIÊNCIA E TECNOLOGIA BAIANO. Regimento interno do núcleo de inovação tecnológica IF BAIANO. Salvador: IF Baiano, 2016a. Disponível em: http://ifBaiano.edu.br/portal/pesquisa/wp-content/uploads/sites/3/2017/03/ Regimento_NIT.pdf. Acesso em: 15 ago. 2019.

IF BAIANO - INSTITUTO FEDERAL DE EDUCAÇÃO, CIÊNCIA E TECNOLOGIA BAIANO. Relatório de Gestão 2018. Salvador: IF Baiano, 2018. Disponível em: http://ifBaiano.edu.br/ portal/wp-content/uploads/2019/06/Relat\%C3\%B3rio-de-Gest\%C3\%A3o-2018.pdf. Acesso em: 3 ago. 2019.

IF BAIANO - INSTITUTO FEDERAL DE EDUCAÇÃO, CIÊNCIA E TECNOLOGIA BAIANO. Resolução n. 31 de novembro de 2015. Aprovar as Normas Regulamentadoras das Atividades de Pesquisa e Inovação no âmbito dos Campi do IF Baiano, de acordo com as deliberações do CONSUP. Salvador: IF Baiano, 2015. Disponível em: http://ifBaiano.edu.br/portal/pesquisa/ resolucao-normas-regulamentadoras-das-atividades-de-pesquisa-inovacao-campi/. Acesso em: 27 set. 2019.

IF BAIANO - INSTITUTO FEDERAL DE EDUCAÇÃO, CIÊNCIA E TECNOLOGIA BAIANO. Resolução/CONSUP n. 35, de $1^{\circ}$ de setembro de 2016. Aprova o regimento interno do núcleo de inovação tecnológica IF BAIANO. Salvador: IFBAIANO, 2016b. Disponível em: http:// ifBaiano.edu.br/portal/wp-content/uploads/2015/12/Resolu\%C3\%A7\%C3\%A3o-35-2016-Aprovouo-Regimento-do-N\%C3\%BAcleo-de-Inova\%C3\%A7\%C3\%A3o-Tecnol\%C3\%B3gica-NIT-no\%C3\%A2mbito-do-IF-Baiano.pdf. Acesso em: 15 ago. 2019.

MAXIMIANO, Antônio Cesar Amaru. Introdução à Administração. 5. ed. ver. e ampl. São Paulo: Atlas, 2000 . 
OCDE - ORGANIZAÇÃO PARA A COOPERAÇÃO E DESENVOLVIMENTO ECONÔMICO. Manual de Oslo 2018: Guidelines for collectingandusing data oninnovation. 4th Edition, Paris/ Eurostat, Luxembourg, 2018. Disponível em: https:/www.mctic.gov.br/mctic/export/sites/institucional/ indicadores/detalhe/Manuais/OCDE-Manual-de-Oslo-4-edicao-em-ingles.pdf. Acesso em: 22 set. 2019.

OLIVEIRA, Ana Cláudia Sá. Aplicação do balancedscorecard à gestão estratégica do instituto federal de educação ciência e tecnologia da Bahia. 2014. 107f. Dissertação (Mestrado em Propriedade Intelectual e Transferência de Tecnologia para a inovação) - Instituto Federal de Educação, Ciência e Tecnologia da Bahia, Salvador, 2014.

REZENDE, Denis Alcides. Planejamento Estratégico para organizações públicas e privadas: guia prático para elaboração do projeto de plano de negócios. Rio de Janeiro: Brasport, 2008. Disponível em: https://books.google.com.br/books?hl=pt-BR\&lr=\&id=dMy8aSbkmz4C\&oi=f nd\&pg $=$ PA1\&dq $=$ conceito + de + planejamento + estrat\%C3\%A9gico\&ots $=$ Lfv1TTVnqw\&sig $=$ nTP9EBWNrjyc7RQCms30hH5VYi0\#v=onepage\&q=conceito\%20de\%20planejamento\%20 estrat\%C3\%A9gico\&f=false. Acesso em: 7 ago. 2019.

VERGARA, Sylvia Constant. Projetos e relatórios de pesquisa em administração. 16. ed. São Paulo: Atlas, 2016.

\section{Sobre os Autores}

\section{Sandra Santos Souza}

E-mail: sandrarb77@bol.com.br

Especialista em Direito Administrativo pela Faculdade Integrada da Grande Fortaleza em 2013.Endereço profissional: Instituto Federal de Educação, Ciência e Tecnologia, Campus Salvador, Rua Emídio dos Santos, s/n, Barbalho, Salvador, BA. CEP: 40301-015.

\section{André Luis Rocha de Souza}

E-mail: profandre.ifba@gmail.com

Doutor em Engenharia Industrial pela Universidade Federal da Bahia em 2016.

Endereço profissional: Instituto Federal de Educação, Ciência e Tecnologia, Campus Salvador, Rua Emídio dos Santos, s/n, Barbalho, Salvador, BA. CEP: 40301-015.

\section{Ângela Maria Ferreira Lima}

E-mail: angela.lima@gmail.com

Doutora em Energia e Ambiente pela Universidade Federal da Bahia em 2017.

Endereço profissional: Instituto Federal de Educação, Ciência e Tecnologia, Campus Salvador, Rua Emídio dos Santos, s/n, Barbalho, Salvador, BA. CEP: 40301-015.

\section{Márcio Luis Valença Araújo}

E-mail: maraujo.valenca@gmail.com

Doutor em Modelagem Computacional e Tecnologia Industrial pelo Senai CIMATEC em 2018.

Endereço profissional: Instituto Federal de Educação, Ciência e Tecnologia, Campus Santo Amaro, Travessa Santo Amaro, n. 44, Santo Amaro, BA. CEP: 44200-000. 